\title{
Clinicopathologic features of cutaneous metastases from internal malignancies
}

\author{
Hyeong Mok Kwon ${ }^{1 *}$, Gyu Yeong Kim ${ }^{2 * *}$, Dong Hoon Shin ${ }^{1}$, Young Kyung Bae ${ }^{3}$ \\ ${ }^{1}$ Department of Dermatology, Yeungnam University College of Medicine, Daegu; \\ ${ }^{2}$ Yeungnam University College of Medicine, Daegu; \\ ${ }^{3}$ Department of Pathology, Yeungnam University College of Medicine, Daegu, Korea
}

\begin{abstract}
Background: Cutaneous metastasis (CM) is the spread of cancer cells from a primary site to the skin and is rarely the first sign of silent cancer. We investigated the clinicopathological characteristics of CM from internal malignancies in Korean patients treated at our institution over 20 years. Methods: The clinicopathological findings of 112 patients (62 females, 50 males) with CM diagnosed at Yeungnam University Hospital between 2000 and 2020 were retrospectively reviewed. Results: Mean patient age was 58.6 years (range, 26 to 87 years), and the most common primary cancer site was breast (74.2\%) in women and lung (36.0\%) in men. Ninety-six patients (85.7\%) presented with $\mathrm{CM}$ after primary tumor diagnosis. CM from the lung or biliary tract usually occurred within 2 years of primary tumor diagnosis, whereas metastases from the breast and kidney occurred several years later. The chest, abdomen, and scalp were common sites of CM. Breast cancer usually metastasized to chest skin, while gastrointestinal tract cancers commonly metastasized to the abdomen. The scalp was a common location for $\mathrm{CM}$ from various tumors. The most common dermatologic presentations were nodules and masses. Immunohistochemical studies helped identify underlying malignancies when primary tumors were unknown. Conclusions: The relative frequency of CM parallels the overall incidence of primary malignant tumors, and CMs usually occur at anatomic sites close to the primary tumor. CM can be diagnosed based on clinical, radiological, and histological features; however, immunohistochemical study is required in some cases.
\end{abstract}

Key Words: Carcinoma; Metastasis; Skin, Immunohistochemistry

Received: February 25, 2021 Revised: April 22, 2021 Accepted: May 24, 2021

Corresponding Author: Young Kyung Bae, MD, PhD, Department of Pathology, Yeungnam University College of Medicine, 170 Hyeonchung-ro, Nam-gu, Daegu 42415, Korea Tel: +82-53-640-6755, Fax: +82-53-622-8432, E-mail: ykbae@ynu.ac.kr

*Hyeong Mok Kwon and Gyu Yeong Kim contributed equally to this work.

"Kyu Young Kim is currently an intern at Samsung Medical Center.

Cutaneous metastases (CMs) from internal malignancies are considered a sign of systemic cancer spread. However, CM can emerge at the same time as the internal malignancy and in rare cases can be the first clinical presentation of occult or unknown primary tumor. While single case reports of $\mathrm{CM}$ from various cancers have been reported in Korea [1-9], systematic reviews on the common clinical and morphological presentations and histological subtypes of $\mathrm{CM}$ are rare. A recent Korean study reviewed data from 401 patients with $\mathrm{CM}$ and reported that the two most common primary cancers were breast and lung cancer [10], and this finding was consistent with those of studies conducted in other ethnic groups [11-15].

This study was undertaken to document the clinicopathologic features of $\mathrm{CM}$ from internal malignancies and primary tumor types, anatomic locations, times between primary tumor diagnoses and development of CMs, and immunohistochemical results of metastatic carcinomas from an unknown origin at the time of $\mathrm{CM}$ diagnosis. In addition, we sought to determine whether the frequency of $\mathrm{CM}$ reflects the incidence of corresponding primary tumors in Korean patients.

\section{MATERIALS AND METHODS}

\section{Case selection}

Consecutive cases with cutaneous metastatic carcinoma biopsied at Yeungnam University Medical Center (YUMC) between 
January 2000 and July 2020 were selected for this study. CM presented as a tumor center in the dermis or subcutaneous tissue, and no features suggestive of primary neoplasm derived from skin appendages. When a patient had multiple synchronous $\mathrm{CMs}$, the largest lesion was considered representative. Metastases from skin malignancies (melanomas or carcinomas), mammary Paget disease, sarcomas, hematolymphoid neoplasms, and/or carcinomas located in a biopsy scar or surgical wound site were excluded.

All histologic findings of hematoxylin and eosin-and immunohistochemically-stained slides of skin and corresponding primary tumors were reviewed. Medical records and pathology reports were reviewed for information about sites and dates of diagnoses of primary tumors and clinical presentations of $\mathrm{CM}$. Anatomic locations of $\mathrm{CM}$ were classified into scalp, face, neck, chest, abdomen, back, perineum, upper extremity, or lower extremity. For cases with multiple $\mathrm{CMs}$, anatomic location was categorized based on the largest lesion. Multifocality was defined as presence of multiple CMs in two or more anatomic locations.

\section{Statistical analysis}

Statistical analysis was performed using SPSS ver. 25.0 for Windows (IBM Corp., Armonk, NY, USA). The difference of time interval between primary tumor diagnosis and occurrence of $\mathrm{CM}$ according to tumor stage or histologic features was determined using Mann-Whitney or Kruskal-Wallis test followed by the Bonferroni method. Statistical significance was accepted for p-values $<.05$.

\section{RESULTS}

\section{Incidence}

A total of 112 patients (62 females, 50 males) with CM was included in this study. For diagnosis of CM, 79 (69.9\%) patients underwent punch biopsy, and 34 (30.1\%) underwent excision. Mean age at CM diagnosis was 58.6 years (median, 59 years; range, 26 to 87 years), and the mean age of women and men was 55.7 and 62.3 years, respectively. Primary tumor was confirmed histologically in 99 patients by surgical resection $(64 \mathrm{pa}-$ tients at Yeungnam University Medical Center and 12 patients at other hospitals) or biopsy (23 patients). In 10 patients, presence of primary tumor was confirmed radiologically. Primary tumor was undetermined in two patients despite extensive workup, and one patient refused further study. Breast (42.0\%) was the most common primary cancer site, followed by lung (18.8\%), stomach $(10.7 \%)$, colon and rectum $(5.4 \%)$, biliary tract $(4.5 \%)$, kidney (3.6\%), and liver (2.7\%) (Table 1). Breast cancer (74.2\%) was the most common primary cancer in female patients, followed by stomach (6.5\%), colorectal (4.8\%), and lung (4.8\%) cancer. In male patients, the most common primary cancer sites were lung $(36.0 \%)$, stomach $(16.0 \%)$, biliary tract $(8.0 \%)$, and kidney (8.0\%) (Table 1). Tumor stage, either pathologic or clinical, was available in 103 patients and distributed as follows:

Table 1. Underlying primary tumors according to sex and stage

\begin{tabular}{|c|c|c|c|c|}
\hline Primary malignancy & Stage & Total & Female & Male \\
\hline \multirow[t]{6}{*}{ Breast } & & $47(42.0)$ & $46(74.2)$ & $1(2.0)$ \\
\hline & I & 5 & 5 & 0 \\
\hline & $\|$ & 15 & 15 & 0 \\
\hline & |l| & 22 & 22 & 0 \\
\hline & IV & 4 & 4 & 0 \\
\hline & Unknown & 1 & 0 & 1 \\
\hline \multirow[t]{5}{*}{ Lung } & & $21(18.8)$ & $3(4.8)$ & $18(36.0)$ \\
\hline & 1 & 1 & 1 & 0 \\
\hline & $\|$ & 1 & 0 & 1 \\
\hline & $\|$ & 4 & 0 & 4 \\
\hline & IV & 15 & 2 & 13 \\
\hline \multirow[t]{4}{*}{ Stomach } & & $12(10.7)$ & $4(6.5)$ & $8(16.0)$ \\
\hline & $\|$ & 1 & 1 & 0 \\
\hline & $\|$ & 8 & 2 & 6 \\
\hline & IV & 3 & 1 & 2 \\
\hline \multirow[t]{3}{*}{ Colorectum } & & $6(5.4)$ & $3(4.8)$ & $3(6.0)$ \\
\hline & $\|$ & 5 & 3 & 2 \\
\hline & IV & 1 & 0 & 1 \\
\hline \multirow[t]{4}{*}{ Biliary tract } & & $5(4.5)$ & $1(1.6)$ & $4(8.0)$ \\
\hline & III & 1 & 0 & 1 \\
\hline & IV & 3 & 0 & 3 \\
\hline & Unknown & 1 & 1 & 0 \\
\hline \multirow[t]{3}{*}{ Kidney } & & $4(3.6)$ & 0 & $4(8.0)$ \\
\hline & IV & 2 & 0 & 2 \\
\hline & Unknown & 2 & 0 & 2 \\
\hline \multirow[t]{4}{*}{ Liver } & & $3(2.7)$ & $1(1.6)$ & $2(4.0)$ \\
\hline & $\|$ & 1 & 1 & 0 \\
\hline & $\|$ & 1 & 0 & 1 \\
\hline & Unknown & 1 & 0 & 1 \\
\hline \multirow[t]{3}{*}{ Salivary gland } & & $2(1.8)$ & 0 & $2(4.0)$ \\
\hline & $\|$ & 1 & 0 & 1 \\
\hline & IV & 1 & 0 & 1 \\
\hline Esophagus & Unknown & $1(0.9)$ & 0 & $1(2.0)$ \\
\hline Lacrimal gland & $\|$ & $1(0.9)$ & 0 & $1(2.0)$ \\
\hline Larynx & IV & $1(0.9)$ & 0 & $1(2.0)$ \\
\hline Pancreas & IV & $1(0.9)$ & $1(1.6)$ & 0 \\
\hline Paranasal sinus & IV & $1(0.9)$ & 0 & $1(2.0)$ \\
\hline Prostate & IV & $1(0.9)$ & 0 & $1(2.0)$ \\
\hline Thyroid & I & $1(0.9)$ & $1(1.6)$ & 0 \\
\hline Tongue & III & $1(0.9)$ & $1(1.6)$ & 0 \\
\hline Tonsil & IV & $1(0.9)$ & 0 & $1(2.0)$ \\
\hline Unknown & Unknown & $3(2.7)$ & $1(1.6)$ & $2(4.0)$ \\
\hline Total & & $112(100)$ & $62(100)$ & $50(100)$ \\
\hline
\end{tabular}

Values are presented as number (\%). 
stage I in 7 (6.8\%), stage II in 19 (18.4), stage III in 43 (41.7\%), and stage IV in $34(33.0 \%)$ patients. Six patients had no record of tumor stage (five patients underwent surgery at other hospitals and stage work-up was not performed in one patient), and primary tumors were unknown in three patients. Tumor stage according to primary site is listed in Table 1.

\section{Histologic features of primary tumors}

The histologic types of common primary tumors with $\mathrm{CM}$ are listed in Table 2. Primary breast cancers were invasive carcinoma of no special type (invasive ductal carcinoma) in 42 (89.4\%) patients, invasive micropapillary carcinoma in two (4.3\%), invasive lobular carcinoma in one (2.1\%), metaplastic carcinoma

Table 2. Histologic type of most frequent primary tumors

\begin{tabular}{|c|c|c|c|}
\hline Primary site & No. & Histologic type & No. \\
\hline \multirow[t]{6}{*}{ Breast } & 47 & & \\
\hline & & Invasive carcinoma, no special type & 42 \\
\hline & & Invasive micropapillary carcinoma & 2 \\
\hline & & Invasive lobular carcinoma & 1 \\
\hline & & Metaplastic carcinoma & 1 \\
\hline & & Unknown & 1 \\
\hline \multirow[t]{4}{*}{ Lung } & 21 & & \\
\hline & & Squamous cell carcinoma & 10 \\
\hline & & Adenocarcinoma & 10 \\
\hline & & Small cell carcinoma & 1 \\
\hline \multirow[t]{4}{*}{ Stomach } & 12 & & \\
\hline & & Adenocarcinoma & 10 \\
\hline & & Mucinous carcinoma & 1 \\
\hline & & Signet ring cell carcinoma & 1 \\
\hline \multirow[t]{4}{*}{ Colorectum } & 6 & & \\
\hline & & Adenocarcinoma & 4 \\
\hline & & Invasive micropapillary carcinoma & 1 \\
\hline & & Signet ring cell carcinoma & 1 \\
\hline
\end{tabular}

in one $(2.1 \%)$, and unknown in one $(2.1 \%)$. Breast molecular subtypes were luminal, triple-negative, human epidermal growth factor receptor 2-positive, and unknown in 21 (44.7\%), 13 (27.7\%), eight (17.0\%), and five (10.6\%) patients, respectively. Histologic grades were 1 in two (4.3\%), 2 in 10 (21.3\%), 3 in 30 $(63.8 \%)$, and unknown in five (10.6\%) patients. Presence or absence of lymphovascular invasion was available in 39 patients, $32(82.1 \%)$ of whom showed lymphovascular invasion.

Of the 21 lung cancers with CM, 10 (47.6\%) were squamous cell carcinomas, 10 (47.6\%) were adenocarcinomas, and one (4.8\%) was small cell carcinoma (Fig. 1). Of the 12 gastric adenocarcinomas with CM, eight $(66.7 \%)$ were poorly differentiated, and the other four were either well differentiated, moderately differentiated, mucinous, or signet ring cell morphologies. For the six colorectal cancers, four were moderately differentiated adenocarcinomas, one was micropapillary carcinoma, and one was signet ring cell carcinoma.

All metastatic renal cell carcinomas were of the clear cell type (Fig. 2). The unusual CMs were from invasive ductal carcinoma from the lacrimal gland, adenoid cystic carcinoma from the submandibular gland, and papillary carcinoma from the thyroid gland. Four cases of squamous cell carcinoma of the esophagus, paranasal sinus, tongue, or tonsil developed CM.

\section{Clinical presentation of $\mathrm{CMs}$}

Among the 112 patients, 96 (85.7\%) presented with $\mathrm{CM}$ after primary tumor diagnosis (mean, 41.8 months; range, 1 to 325 months). In 12 patients (10.7\%), CM was found at the same time as internal malignancies, and in four patients (3.6\%), CM was the first sign of internal malignancy. Time between diagnosis of primary tumors and $\mathrm{CM}$ was greater for patients with
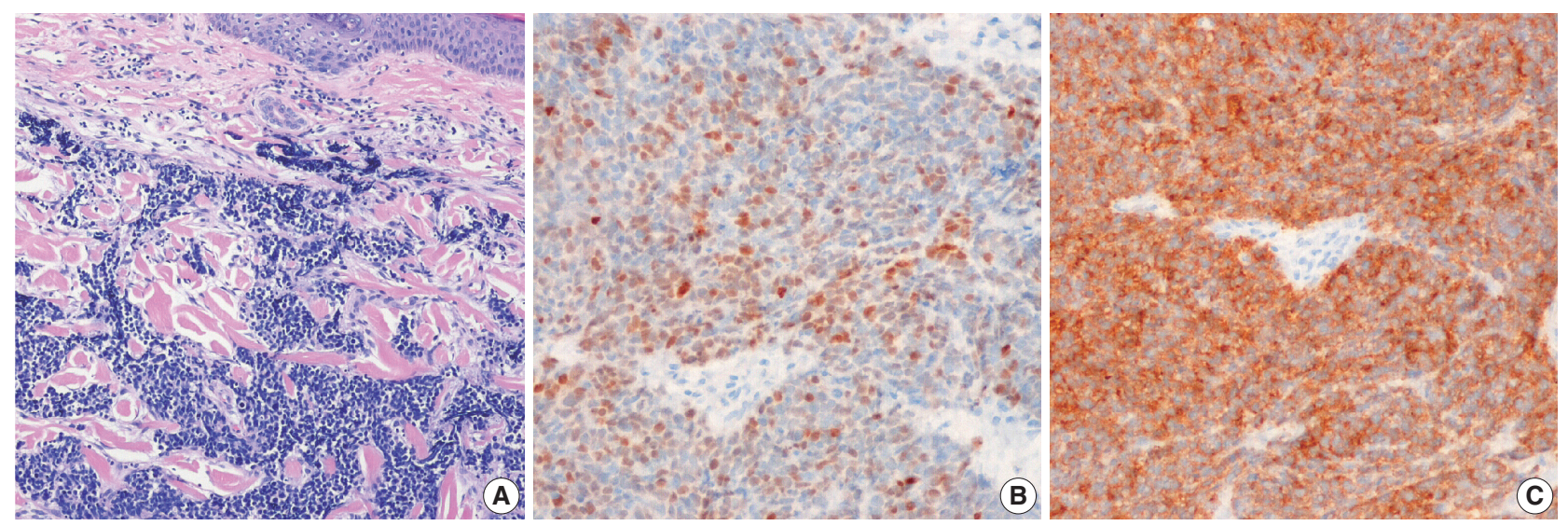

Fig. 1. Metastatic small cell carcinoma of the lung. (A) Tumor cells infiltrated dermal collagen bundles and were diffusely positive for thyroid transcription factor 1 (B) and synaptophysin (C). 

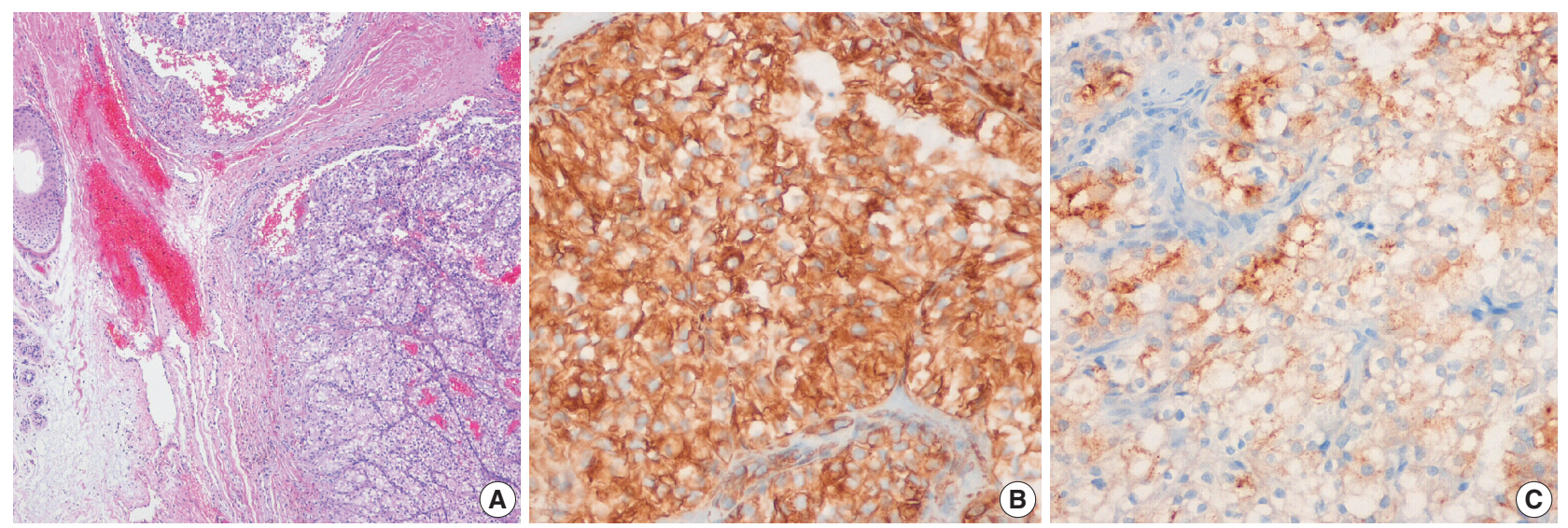

Fig. 2. Metastatic renal cell carcinoma. (A) The tumor was clear cell type, and tumor cells were positive for vimentin (B) and renal cell carcinoma (C).

breast or kidney cancer than for those with lung or biliary tract cancer (Table 3, Fig. 3). In breast cancer patients, tumor stage was significantly associated with time interval between primary tumor diagnosis and $\mathrm{CM}(\mathrm{p}<.001)$. Stage II or III tumors showed a longer time interval between primary tumor diagnosis and CM than did stage IV tumors (Table 3). However, there was no statistical difference in time interval between diagnosis of breast cancer and $\mathrm{CM}$ according to presence or absence of lymphovascular invasion or histologic grade of the primary tumor (Supplementary Table S1). Due to the small number of patients, the same statistical analysis could not be performed for other primary tumors.

Forty-nine patients (43.4\%) had multiple CM lesions, and $12(10.7 \%)$ presented with multiple CMs at two or more anatomic locations (Table 4). About 70\% of the 112 patients were asymptomatic, but others experienced tenderness (16.1\%), oozing $(6.3 \%)$, and pain (5.4\%). The most common dermatologic presentations of $\mathrm{CM}$ were nodules (53.6\%) or masses (19.6\%), followed by papules $(12.5 \%)$, plaques $(9.8 \%)$, or ulcers $(2.7 \%)$ (Table 4).

The common sites of $\mathrm{CM}$ were chest (35.7\%), head and neck (34.8\%; scalp, 16.1\%; neck, 9.8\%; face, 8.9\%), and abdomen (17.9\%) (Fig. 4). Breast cancer usually metastasized to the chest, lung cancer to the head and neck or chest, and gastrointestinal tract cancer to the abdomen or scalp.

\section{Immunohistochemical markers that define primary sites}

The primary tumor was unable to be confirmed histologically in 12 patients with CM. In these cases, primary tumor sites were identified based on immunohistochemical staining results of skin lesions and radiologic findings (Table 5).

Five patients had lung masses revealed by chest computed tomography (CT) or positron emission tomography (PET)-CT. In four of these cases, the $\mathrm{CM}$ was adenocarcinomas; the other was squamous cell carcinoma. In all five patients, $\mathrm{CMs}$ were positive for cytokeratin 7 (CK7), four adenocarcinomas were negative for CK20, and two patients were positive for thyroid transcription factor 1 (TTF-1). Metastatic squamous cell carcinoma was positive for p63 and p40.

One patient had metastatic adenocarcinoma masses of the face and liver by PET-CT. Tumor cells in this patient were positive for CK7, CK19, and CK20 and negative for TTF- 1 and caudaltype homeobox 2 (CDX2), which suggested biliary tract origin (Fig. 5). Interestingly, one female patient with metastatic carcinoma of the left chest skin was suspected of having breast cancer because tumor cells were positive for mammaglobin and progesterone receptor (PR) but negative for estrogen receptor (ER) and gross cystic disease fluid protein 15 (GCDFP-15). PET-CT of this patient depicted hypermetabolic areas in the left breast, axillary lymph nodes, and multiple bones.

One male patient with metastatic adenocarcinoma of the upper extremity skin had a prostatic mass and multiple lung and bone lesions. Tumor cells in a lung mass biopsy were positive for P504S but negative for TTF-1, although the metastatic adenocarcinoma was negative for $\mathrm{P} 504 \mathrm{~S}$ and prostatic specific antigen. Another patient with metastatic carcinoma in the abdominal skin that was morphologically consistent with clear renal cell carcinoma had a hypermetabolic mass on PET-CT in the right kidney. Tumor cells from the skin lesion were positive for paired box gene 8 (PAX8). In one female patient with metastatic adenocarcinoma of the scalp, PET-CT depicted multiple masses in the liver, adrenals, kidneys, ovaries, and omentum. Tumor cells from the scalp were positive for $\mathrm{CK} 7$, CK19, and PAX8 but negative for CK20, CDX2, TTF-1, WT-1, ER, and PR. In this patient, 
Table 3. Time interval between diagnosis of primary malignancy and cutaneous metastasis in patients who developed cutaneous metastasis after diagnosis of primary malignancy

\begin{tabular}{|c|c|c|c|}
\hline Primary site & Stage & No. & $\begin{array}{l}\text { Time interval between diagnosis } \\
\text { of primary tumor and occurrence } \\
\text { of cutaneous metastasis }{ }^{\mathrm{a}}(\mathrm{mo})\end{array}$ \\
\hline \multirow[t]{6}{*}{ Breast } & & 46 & $1-325(58.9 \pm 60.5)$ \\
\hline & । & 5 & $25-149(84.0 \pm 58.4)$ \\
\hline & $\|$ & 15 & $11-188(71.9 \pm 51.4)$ \\
\hline & III & 22 & $1-325(48.1 \pm 70.1)$ \\
\hline & IV & 3 & $24-53(36.0 \pm 15.1)$ \\
\hline & Unknown & 1 & 42 \\
\hline \multirow[t]{5}{*}{ Lung } & & 14 & $1-29(12.5 \pm 9.5)$ \\
\hline & । & 1 & 3 \\
\hline & $\|$ & 1 & 13 \\
\hline & III & 4 & $2-26(15.8 \pm 10.4)$ \\
\hline & IV & 8 & $1-29(12.0 \pm 10.2)$ \\
\hline \multirow[t]{4}{*}{ Stomach } & & 11 & $1-47(20.8 \pm 17.9)$ \\
\hline & $\|$ & 1 & 31 \\
\hline & III & 8 & $1-47(19.9 \pm 19.1)$ \\
\hline & IV & 2 & $3-36$ \\
\hline Colorectum & III & 5 & $3-58(26.4 \pm 21.5)$ \\
\hline \multirow[t]{3}{*}{ Kidney } & & 4 & $4-180(61.0 \pm 80.4)$ \\
\hline & IV & 2 & $4-35$ \\
\hline & Unknown & 2 & $25-180$ \\
\hline \multirow[t]{4}{*}{ Biliary tract } & & 3 & $3-23(13.3 \pm 10.0)$ \\
\hline & III & 1 & 23 \\
\hline & IV & 1 & 3 \\
\hline & Unknown & 1 & 14 \\
\hline \multirow[t]{4}{*}{ Liver } & & 3 & \\
\hline & $\|$ & 1 & 64 \\
\hline & III & 1 & 87 \\
\hline & Unknown & 1 & - \\
\hline \multirow[t]{3}{*}{ Salivary gland } & & 2 & \\
\hline & III & 1 & 30 \\
\hline & IV & 1 & 25 \\
\hline Esophagus & Unknown & 1 & 7 \\
\hline Lacrimal gland & $\|$ & 1 & 39 \\
\hline Larynx & IV & 1 & 30 \\
\hline Pancreas & IV & 1 & 9 \\
\hline Paranasal sinus & IV & 1 & 2 \\
\hline Thyroid & I & 1 & 120 \\
\hline Tongue & III & 1 & 17 \\
\hline Tonsil & IV & 1 & 11 \\
\hline Total & & 96 & $1-325(41.8 \pm 50.6)$ \\
\hline
\end{tabular}

avalues are presented as range (mean \pm standard deviation).

a primary tumor originating from the ovary or biliary tract was suspected but not confirmed. Despite extensive work-up, primary cancer was not determined in one patient. Another patient refused further work-up aimed at identifying the primary site.

\section{DISCUSSION}

In this study, we retrospectively reviewed 112 cases with CM from internal malignancies in patients treated over 20 years at our institution. Common primary tumor sites differed in female and male patients. Breast and stomach cancer were the most common primary tumors in female patients, while lung and stomach cancers were most common in male patients. Considering that the numbers of breast, gastric, lung, and colorectal cancer patients newly registered at our institution over the past 20 years (January 2000 to December 2020) were 10,890, 9,968, 8,409, and 8,188 patients, respectively, the incidence of $\mathrm{CM}$ might reflect the overall incidence of cancers. According to Korean cancer statistics for 2017 [16], the most common cancer sites were the stomach (12.8\%), colorectum (12.1\%), lung (11.6\%), thyroid (11.3\%), breast $(9.6 \%)$, liver (6.6\%), prostate (5.5\%), pancreas (3\%), biliary tract and gallbladder (2.9\%), and kidney (2.3\%). The most common sites by sex were breast (20.3\%), thyroid (18.3\%), colorectum $(10.4 \%)$, and stomach $(8.9 \%)$ in women and stomach (16.3\%), lung (15.3\%), colorectum (13.6\%), and prostate (10.5\%) in men. These results indicate that the incidence of $\mathrm{CM}$ is proportional to the overall incidence of cancer, with exceptions that lung cancer tended to metastasize more easily than stomach cancer, and that thyroid and prostate cancers rarely gave rise to skin metastases. In addition, the frequency of $\mathrm{CM}$ from breast cancer corresponded to the frequency of histologic and molecular subtypes of primary breast cancer. Previous studies on different ethnic groups, including a Korean study, reported similar results regarding correspondence between $\mathrm{CM}$ frequency and the overall incidence of primary malignant tumors $[10,12-15,17,18]$.

However, time between primary diagnosis and development of $\mathrm{CM}$ varied considerably and depended on primary tumor type. For example, CM from lung and biliary tract cancers usually occurred within two years of primary diagnosis, whereas $\mathrm{CM}$ from breast cancer and hepatocellular and renal cell carcinoma occurred several years after primary diagnosis. Choi et al. [10] also reported that $\mathrm{CM}$ occurred several years (mean, 48.2 months) after diagnosis of hepatocellular carcinoma, while lung and pancreatic cancers metastasized to the skin within one year of primary diagnosis. Furthermore, it was reported in a Taiwanese study that CM occurred early in lung cancer (mean, 15.7 months; range, 1 month to 5 years) but several years after breast cancer excision (mean, 47.2 months; range, 1 month to 10 years) [13].

With regard to metastatic sites, any skin region might be involved, but the chest, head and neck, and abdomen were most affected by CM. In particular, breast cancer usually metastasized to the chest, whereas gastrointestinal tract cancers commonly metastasized to abdominal skin. These results support the notion that $\mathrm{CM}$ is usually found in an anatomic location close to the primary 


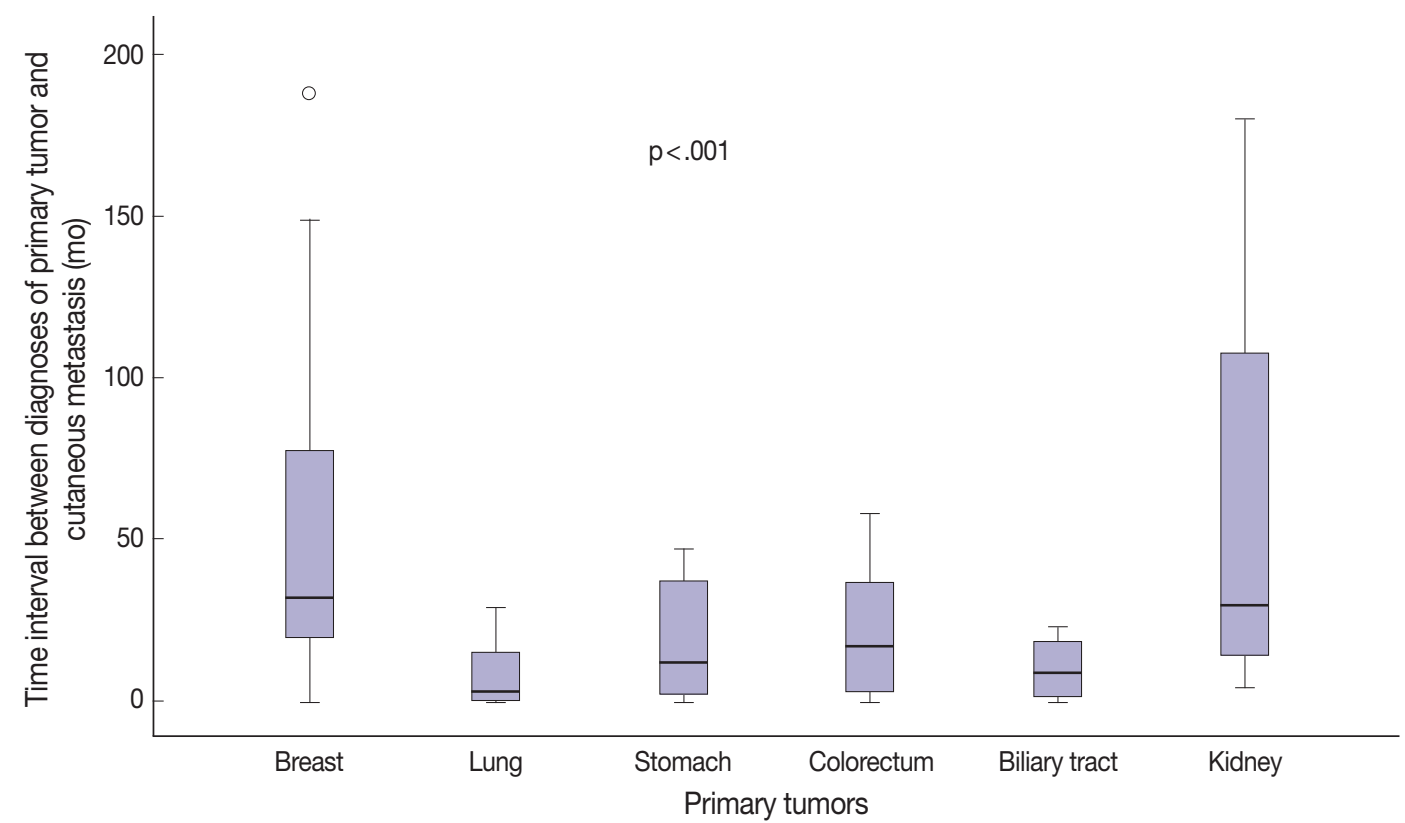

Fig. 3. Comparison of time interval between diagnosis of primary tumor and occurrence of cutaneous metastasis according to primary tumor site.

Table 4. Clinical presentation of cutaneous metastasis

\begin{tabular}{lc}
\hline Clinical presentation & No. of cases (\%) \\
\hline No. of lesions & \\
Single & $63(56.3)$ \\
Multiple & $49(43.8)$ \\
Focality & \\
Unifocal & $100(89.3)$ \\
Multifocal & $12(10.7)$ \\
Symptom & \\
Asymptomatic & $78(69.6)$ \\
Tenderness & $18(16.1)$ \\
Oozing & $7(6.3)$ \\
Pain/Tenderness & $4(3.6)$ \\
Pain & $2(1.8)$ \\
Itching & $2(1.8)$ \\
Bleeding & $1(0.9)$ \\
Dermatologic presentation & \\
Nodule & $60(53.6)$ \\
Mass & $22(19.6)$ \\
Papule & $14(12.5)$ \\
Plaque & $11(9.8)$ \\
Ulcer & $3(2.7)$ \\
Patch & $1(0.9)$ \\
Vesicle & $1(0.9)$ \\
\hline
\end{tabular}

tumor, presumably because epithelial cancer cells predominantly disseminate via lymphatic channels. However, some CMs occurred in regions distant from the primary tumors; for example, the scalp was a common CM location for various tumors. The possible mechanism as to why the scalp is a common destination for $\mathrm{CM}$ is thought to be due to its high vascularity [19].

It has been reported that $2.9 \%$ to $21 \%$ of CMs are found prior to diagnosis of primary cancers $[11,12]$. In the present study, $11.5 \%$ of patients developed CM as the first manifestation of internal malignancy. In this clinical setting, pathologists can use morphologic examinations and immunohistochemical studies to identify underlying primary tumors and provide valuable information for subsequent clinical workup. In metastatic adenocarcinoma, positivity for $\mathrm{CK} 7$, TTF-1, and napsin A and negativity for CK20 indicate a pulmonary origin. Squamous cell carcinoma of the lung typically exhibits CK5/6 and p 40 positivity, and small cell lung carcinoma is positive for TTF-1 but negative for CK7 and CK20 [20]. Metastatic small cell carcinoma of the lung and primary cutaneous Merkel cell carcinoma must be precisely differentiated as they share a neuroendocrine origin and have similar histologic features. CK20 and TTF-1 have been routinely used in this context because small cell lung carcinoma is usually CK20 negative but TTF-1 positive, while primary cutaneous Merkel cell carcinoma is CK20 positive (characteristically paranuclear dotlike) and TTF-1 negative in most cases $[21,22]$. However, about $10 \%$ of Merkel cell carcinomas are positive for TTF-1 and negative for CK20 [23].

The histologic features of metastatic breast cancer can be similar to those of primary cutaneous adnexal malignancies, and both are positive for $\mathrm{CK} 7$ and negative for CK20. ER, PR, mammaglobin, and GCDFP-15 are useful markers of breast origin 
$[21,24,25]$, but only $50 \%$ of metastatic breast carcinomas are ER positive and 65\%-70\% are mammaglobin positive. Gynecological malignancies occasionally exhibit ER and/or PR positivity
[26-28]. These findings indicate that immunohistochemical results should be considered alongside clinical and radiological findings. For gastrointestinal tract malignancies, CK7, CK20, and
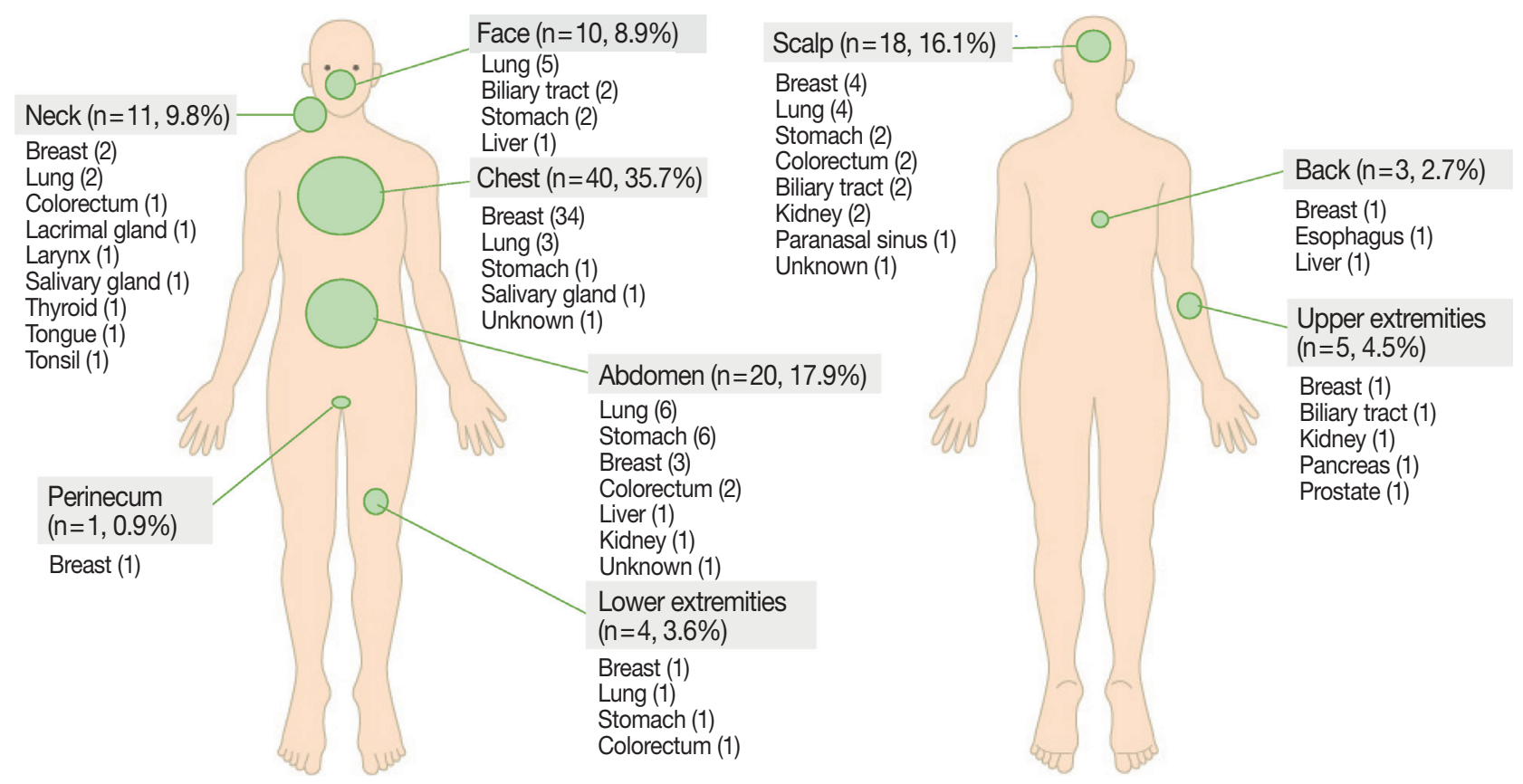

Fig. 4. Incidence of cutaneous metastasis by anatomic location and primary tumor site.

Table 5. Clinicopathologic features of cases with cutaneous metastasis in which the primary tumor was not confirmed histologically

\begin{tabular}{|c|c|c|c|c|c|c|c|}
\hline \multirow{2}{*}{ No. } & \multirow{2}{*}{$\begin{array}{l}\text { Age } \\
(y r)\end{array}$} & \multirow{2}{*}{ Sex } & \multicolumn{3}{|c|}{ Cutaneous metastasis } & \multirow{2}{*}{ Radiologic findings } & \multirow{2}{*}{$\begin{array}{l}\text { Suggested } \\
\text { primary site }\end{array}$} \\
\hline & & & Location & Histology & Immunohistochemical results & & \\
\hline 1 & 62 & $\mathrm{M}$ & Axilla & Adenocarcinoma & TTF-1+, CK7+, CK20-, CDX2- & $\begin{array}{l}\text { Multiple masses in lungs, liver, bone, and } \\
\text { LNs on PET-CT }\end{array}$ & Lung \\
\hline 2 & 61 & M & Abdomen & Adenocarcinoma & TTF-1-, CK7+, CK20-, Napsin A- & Lung mass on CT & Lung \\
\hline 3 & 58 & M & $\begin{array}{l}\text { Scalp, } \\
\text { Abdomen }\end{array}$ & Adenocarcinoma & TTF-1-, CK7+, CK20- & $\begin{array}{l}\text { Lung mass on CT, suspicious metastases } \\
\text { to hilar, subaortic, subcarninal LNs, } \\
\text { and both adrenals }\end{array}$ & Lung \\
\hline 4 & 55 & M & Scalp & Adenocarcinoma & TTF-1+, CK7+, CK20- & $\begin{array}{l}\text { Lung mass on PET-CT, metastases } \\
\text { to multiple LNs and bones }\end{array}$ & Lung \\
\hline 5 & 76 & M & Chest & $\begin{array}{l}\text { Squamous cell } \\
\text { carcinoma }\end{array}$ & CK7 focal+, p63+, p40+ & Lung mass on CT & Lung \\
\hline 6 & 68 & M & Face & Adenocarcinoma & CK7+, CK19+, CK20+, TTF-1-, CDX2- & $\begin{array}{l}\text { Liver masses on PET-CT without } \\
\text { histologic confirmation }\end{array}$ & Biliary tract \\
\hline 7 & 58 & $\mathrm{~F}$ & Chest & Carcinoma & ER-, PR+, Mammaglobin+, GCDFP-15- & $\begin{array}{l}\text { Left breast mass on PET-CT, } \\
\text { metastases to bone and axillary LNs }\end{array}$ & Breast \\
\hline 8 & 72 & M & $\begin{array}{l}\text { Upper } \\
\text { extremity }\end{array}$ & Adenocarcinoma & $\begin{array}{l}\text { PSA-, P504S- } \\
\text { Lung mass: TTF-1-, c-Met+, CK7+, } \\
\text { P504S+, ERG- }\end{array}$ & $\begin{array}{l}\text { Prostatic mass on PET-CT, multiple lung } \\
\text { masses, metastases to multiple bones }\end{array}$ & Prostate \\
\hline 9 & 74 & M & Abdomen & $\begin{array}{l}\text { Renal cell } \\
\text { carcinoma }\end{array}$ & PAX8+, RCC- & $\begin{array}{l}\text { Right kidney mass on PET-CT, } \\
\text { metastases to multiple bones }\end{array}$ & Kidney \\
\hline 10 & 36 & $\mathrm{~F}$ & Scalp & Adenocarcinoma & $\begin{array}{l}\text { CK7+, CK19+, PAX8+, CK20-, CDX2-, } \\
\text { TTF-1-, WT-1-, ER-, PR- }\end{array}$ & $\begin{array}{l}\text { Multiple masses in liver, adrenals, kidneys, } \\
\text { ovaries, and omentum on PET-CT }\end{array}$ & Unknown \\
\hline 11 & 67 & M & Axilla & Carcinoma & $\begin{array}{l}\text { GATA3+, CK7-, CK20-, PSA-, } \\
\text { TTF-1-, CDX2- }\end{array}$ & No suggested primary tumor on PET-CT & Unknown \\
\hline 12 & 57 & M & Trunk & Adenocarcinoma & $\begin{array}{l}\text { CK7+, CK19+, CK20-, CDX2 focal+, } \\
\text { TTF-1- }\end{array}$ & No further study & Unknown \\
\hline
\end{tabular}

M, male; TTF-1, thyroid transcription factor 1; CK, cytokeratin; LN, lymph node; PET-CT, positron emission tomography-computed tomography; ER, estrogen receptor; PR, progesterone receptor; GCDFP-15, gross cystic disease fluid protein 15; PSA, prostate specific antigen; RCC, renal cell carcinoma. 

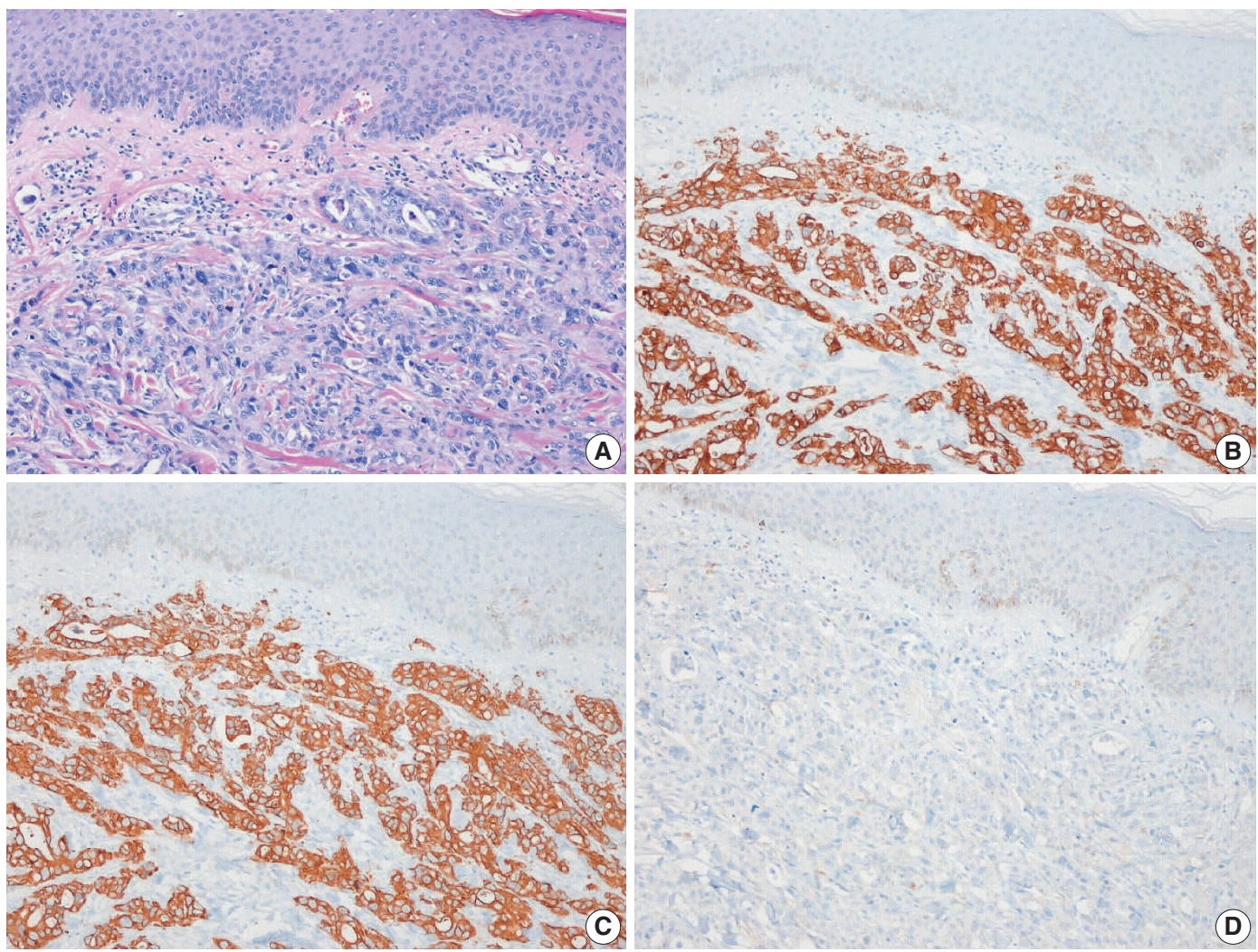

Fig. 5. Representative histologic features and immunohistochemical staining results for metastatic adenocarcinoma of the face. (A) Poorly differentiated adenocarcinoma was mainly located in the dermis. Tumor cells were positive for cytokeratin (CK) 7 (B) and CK19 (C) but negative for thyroid transcription factor 1 (D). Although no primary tumor was confirmed histologically, the metastatic adenocarcinoma was considered of biliary tract origin.

$\mathrm{CDX} 2$ can help determine tumor origin. Gastric cancer is generally positive for $\mathrm{CK} 7$ and $\mathrm{CK} 20$, whereas colorectal cancer is negative for $\mathrm{CK} 7$ and positive for $\mathrm{CK} 20$ and $\mathrm{CDX} 2$. In hepatocellular carcinoma, hepatocyte paraffin 1 (HepPar-1), arginase 1, and $\alpha$-fetoprotein can help confirm diagnosis [20,29]. Renal cell carcinoma shows negativity for $\mathrm{CK} 7$ and CK20 and positivity for renal cell carcinoma marker and PAX8 [20]. Gynecological cancers exhibit a variety of immunohistochemical profiles and are generally positive for cancer antigens $125, \mathrm{CK} 7$, and CK20 [21], though ovarian cancer and endometrial cancer are also PAX8 positive [30].

In conclusion, although CMs are rarely observed after diagnosis of primary internal malignancies, they occur at rates that are approximately proportional to the frequency of the primary tumor. The most common primary cancer sites in this retrospective study was breast in women and lung in men. Lung and biliary tract cancers usually metastasized to the skin within 2 years of primary cancer diagnosis, whereas metastases from breast cancer, hepatocellular carcinoma, and renal cell carcinoma occurred several years later. Although metastasis to the skin can occur at any location, the chest, head and neck, and abdomen were most commonly affected. CM can be diagnosed by clinical, radiological, and histological examinations, although in some cases immunohistochemical studies are required.

\section{Supplementary Information}

The Data Supplement is available with this article at https://doi.org/10.4132/ jptm.2021.05.24.

\section{Ethics Statement}

This study was approved by the Institutional Review Board (IRB) of Yeungnam University Medical Center (YUMC2020-06-092), with a waiver of the requirement for informed consent.

\section{Availability of Data and Material}

The data that support the findings of this study are available from the corresponding author upon reasonable request.

\section{Code Availability}

Not applicable. 


\section{ORCID}

Hyeong Mok Kwon Gyu Yeong Kim Dong Hoon Shin Young Kyung Bae http://orcid.org/0000-0002-1557-1370 http://orcid.org/0000-0003-3130-3699 http://orcid.org/0000-0002-6689-9413 http://orcid.org/0000-0003-4062-3184

\section{Author Contributions}

Conceptualization: YKB. Data curation: HMK, GYK. Formal analysis: GYK, YKB. Funding acquisition: YKB. Investigation: YKB, DHS. Methodology: HMK, GYK, DHS, YKB. Project administration: YKB. Validation: YKB. Writing - original draft: HMK, GYK, YKB. Writing_review \& editing: HMK, GYK, DHS, YKB. Approval of final manuscript: HMK, GYK, DHS, YKB. Approval of final manuscript: all authors.

\section{Conflicts of Interest}

The authors declare that they have no potential conflicts of interest.

\section{Funding Statement}

This work was supported by the 2020 Yeungnam University Research Grant (220A480010).

\section{References}

1. Moon JI, Park JY, Jeon TJ, et al. Non-umbilical cutaneous metastasis of pancreatic adenocarcinoma as the first clinical manifestation: a case report. Korean J Gastroenterol 2016; 68: 221-4.

2. Kwon MJ, Ryu SH, Jo SY, et al. A case of hepatocellular carcinoma presenting as a gingival mass. Korean J Gastroenterol 2016; 68: 321-5.

3. Song YW, Kim WS, Yun GY, et al. A case of early gastric cancer with nodular tumor-like scalp metastasis. Korean J Gastroenterol 2016; 68: 36-9.

4. Yang HJ, Kang SY. Cutaneous metastatic renal cell carcinoma to the scalp. Arch Craniofac Surg 2019; 20: 392-6.

5. Kim JH, Kim MJ, Sim WY, Lew BL. Alopecia neoplastica due to gastric adenocarcinoma metastasis to the scalp, presenting as alopecia: a case report and literature review. Ann Dermatol 2014; 26: 624-7.

6. Kim MK, Kim SH, Lee YY, et al. Metastatic skin lesions on lower extremities in a patient with recurrent serous papillary ovarian carcinoma: a case report and literature review. Cancer Res Treat 2012; 44: $142-5$.

7. An MK, Park BW, Cho EB, Park EJ, Kim KH, Kim KJ. A case of cutaneous metastasis of nasopharyngeal carcinoma on the face. Korean J Dermatol 2019; 57: 80-3.

8. Hong SG, Jo SY, Jeong HH, et al. Cutaneous metastasis originating from esophageal carcinoma: a case report. Korean J Dermatol 2020; 58: 269-72.

9. Lee JY, Shin SJ, Yoo CS, Kil MS, Kim CW, Kim SS. A case of zosteriform cutaneous metastasis from lung cancer. Korean J Dermatol 2013; 51: 272-5.

10. Choi ME, Jung CJ, Lee WJ, et al. Clinicopathological study of Korean patients with cutaneous metastasis from internal malignancies. Australas J Dermatol 2020; 61: e139-42.

11. Brownstein MH, Helwig EB. Spread of tumors to the skin. Arch Dermatol 1973; 107: 80-6.

12. Lookingbill DP, Spangler N, Sexton FM. Skin involvement as the presenting sign of internal carcinoma: a retrospective study of 7316 cancer patients. J Am Acad Dermatol 1990; 22: 19-26.
13. Hu SC, Chen GS, Lu YW, Wu CS, Lan CC. Cutaneous metastases from different internal malignancies: a clinical and prognostic appraisal. J Eur Acad Dermatol Venereol 2008; 22: 735-40.

14. Sittart JA, Senise M. Cutaneous metastasis from internal carcinomas: a review of 45 years. An Bras Dermatol 2013; 88: 541-4.

15. Handa U, Kundu R, Dimri K. Cutaneous metastasis: a study of 138 cases diagnosed by fine-needle aspiration cytology. Acta Cytol 2017; 61: 47-54.

16. Hong S, Won YJ, Park YR, et al. Cancer statistics in Korea: incidence, mortality, survival, and prevalence in 2017. Cancer Res Treat 2020; 52: 335-50.

17. Gul U, Kilic A, Gonul M, Kulcu Cakmak S, Erinckan C. Spectrum of cutaneous metastases in 1287 cases of internal malignancies: a study from Turkey. Acta Derm Venereol 2007; 87: 160-2.

18. Mok ZR, Yong AM, Leung AJ, Tan KB, Aw DC. Cutaneous metastasis: experience from a tertiary healthcare institution in Singapore. Int J Dermatol 2017; 56: 1497-8.

19. Shah SR, Applebaum DS, Potenziani S, Huttenbach YT, Wolf J, Orengo IF. Cutaneous metastasis to the scalp as the primary presentation of colorectal adenocarcinoma. Dermatol Online J 2017 Nov 15 [Epub]. http://dx.doi.org/10.5070/D32311037274.

20. Habermehl G, Ko J. Cutaneous metastases: a review and diagnostic approach to tumors of unknown origin. Arch Pathol Lab Med 2019; 143: 943-57.

21. Hussein MR. Skin metastasis: a pathologist's perspective. J Cutan Pathol 2010; 37: e1-20.

22. Yang DT, Holden JA, Florell SR. CD117, CK20, TTF-1, and DNA topoisomerase II-alpha antigen expression in small cell tumors. J Cutan Pathol 2004; 31: 254-61.

23. Kervarrec T, Tallet A, Miquelestorena-Standley E, et al. Diagnostic accuracy of a panel of immunohistochemical and molecular markers to distinguish Merkel cell carcinoma from other neuroendocrine carcinomas. Mod Pathol 2019; 32: 499-510.

24. Green AR, Young P, Krivinskas S, et al. The expression of ERalpha, ERbeta and PR in lobular carcinoma in situ of the breast determined using laser microdissection and real-time PCR. Histopathology 2009; 54: 419-27.

25. Matsuoka K, Ohsumi S, Takashima S, Saeki T, Aogi K, Mandai K. Occult breast carcinoma presenting with axillary lymph node metastases: follow-up of eleven patients. Breast Cancer 2003; 10: 330-4.

26. Gomez-Fernandez C, Daneshbod Y, Nassiri M, Milikowski C, Alvarez C, Nadji M. Immunohistochemically determined estrogen receptor phenotype remains stable in recurrent and metastatic breast cancer. Am J Clin Pathol 2008; 130: 879-82.

27. Liu H. Application of immunohistochemistry in breast pathology: a review and update. Arch Pathol Lab Med 2014; 138: 1629-42.

28. Monaco SE, Wu Y, Teot LA, Cai G. Assessment of estrogen receptor (ER), progesterone receptor (PR), and human epidermal growth factor receptor 2 (HER2) status in the fine needle aspirates of metastatic breast carcinomas. Diagn Cytopathol 2013; 41: 308-15.

29. Werling RW, Yaziji H, Bacchi CE, Gown AM. CDX2, a highly sensitive and specific marker of adenocarcinomas of intestinal origin: an immunohistochemical survey of 476 primary and metastatic carcinomas. Am J Surg Pathol 2003; 27: 303-10.

30. Kandalaft PL, Gown AM. Practical applications in immunohistochemistry: carcinomas of unknown primary site. Arch Pathol Lab Med 2016; 140: 508-23. 